\title{
Morphometric and Immunocytochemical Assessment of Fungiform Taste Buds After Interruption of the Chorda-Lingual Nerve
}

\author{
BRUCE OAKLEY, ANNE LAWTON, DAVID R. RIDDLE, AND LAN-HSIN WU \\ Department of Biology, University of Michigan, Ann Arbor, Michigan 48109 (B.O., A.L.); Department of Neurobiology, Duke \\ University Medical Center, Durham, North Carolina 27710 (D.R.R.); Warner-Lambert, Ann Arbor, Michigan 48105 (L.-H.W.)
}

\author{
KEY WORDS Atrophy, Keratin, Monoclonal antibodies, Regeneration, Reinnervation, Tongue
}

\begin{abstract}
Unilateral interruption of the chorda-lingual nerve led to a loss of most epithelial axons and to the deterioration of fungiform taste buds in the anterior portion of the tongue of albino rats, mongolian gerbils, and golden hamsters. By three weeks after surgery the following percentages of fungiform taste buds had completely disappeared: $71 \%$ in gerbils, $28 \%$ in rats, and $26 \%$ in hamsters. Residual taste buds were classified into two groups: atrophic taste buds and taste bud remnants. Atrophic taste buds were smaller than normal and typically had no visible taste pore, although they retained the characteristic oval shape of a taste bud and numerous elongated cells. Taste bud remnants were non-oval fragments of taste buds with few elongated cells. Specific markers for elongated taste cells (monoclonal antibodies to keratin 19) confirmed that atrophic taste buds, as well as some taste bud remnants, had elongated taste cells. By 180 days after chorda-lingual nerve transection, $44 \%$ of rat fungiform taste buds had disappeared; morphometric analysis of the 311 residual taste buds established that 241 atrophic taste buds and 69 taste bud remnants were, respectively, $50 \%$ and $75 \%$ smaller than the average volume of 480 normal taste buds. The aggregate loss of gustatory tissue, calculated from the shrinkage of residual taste buds and the volume lost by the outright disappearance of many taste buds, was $88 \%$ for gerbils, $72 \%$ for rats, and $65 \%$ for hamsters. Evaluation in gerbils of the co-occurrence of taste buds and axons suggests residual taste buds were neurotrophically supported. Every gerbil fungiform papilla that lacked axons lacked a taste bud. Every fungiform papillae that had a residual taste bud had axons; axons were absent from $22 \%$ of empty fungiform papillae. Diminished numbers of gustatory neurotrophic axons could account for both the loss of fungiform taste buds and the reduced volume of residual taste buds. (1) 1993 Wiley-Liss, Inc.
\end{abstract}

\section{INTRODUCTION}

Numerous studies have demonstrated the absolute nerve-dependence of mammalian vallate and foliate taste buds and their restoration by reinnervation (reviewed in Guth, 1971; Oakley, 1985; Ganchrow and Ganchrow, 1989). The less well-established nerve-dependence of fungiform taste buds and the consequences of nerve interruption are the subjects of the present investigation. Not all fungiform taste buds disappear completely after interruption of the chorda tympani and lingual nerves (Farbman, 1969; Cheal and Oakley, 1977; Cheal et al., 1977; Whitehead et al., 1985; Ganchrow and Ganchrow, 1989; Hard af Segerstad et al., 1989). The paucity of axon profiles in electron micrographs of residual fungiform taste buds after lesioning the chorda tympani nerve is consistent with the view that residual taste buds survive without direct nerve contact (Whitehead et al., 1987; Hard af Segerstad et al., 1989). The present investigation broadened the base of examination by quantifying the effects of interruption of the chorda-lingual nerve on the entire population of fungiform taste buds in rat, gerbil, and hamster. The investigation's aims were to count the number of fungiform taste buds lost in operated ani- mals, to quantify the degree of shrinkage of surviving taste buds that were identified and characterized with the aid of taste cell specific markers, and to evaluate whether the surviving fungiform taste buds were nerve-dependent.

\section{MATERIALS AND METHODS Surgical Procedures}

The chorda tympani and the lingual nerves join to form the chorda-lingual nerve (CL), which sends sensory fibers to the anterior two-thirds of the rodent tongue. These nerves were exposed under anesthesia induced by injection of $1 \mathrm{mg}$ of sodium pentobarbital i.p. in conjunction with ketamine $(0.2 \mathrm{mg} / \mathrm{g}$ body weight i.m. in hamsters and rats, and $0.3 \mathrm{mg} / \mathrm{g}$ body weight i.m. in gerbils). The 3-4-month-old animals ate and drank normally within 2 days following unilateral CL

Received February 10, 1992; accepted in revised form February 20, 1992.

Address reprint requests to Bruce Oakley, Department of Biology, 3127 Natural Science Building, University of Michigan, Ann Arbor, MI 48109. 
nerve interruption. Keeping one CL nerve intact prevented animals from injuring their tongues.

Hamsters (Mesocricetus auratus from Harlan Co., $\boldsymbol{n}=5$ ). The left CL nerve was transected where it approaches the tongue medial to the mandible, while the mylohyoid nerve was transected nearby where it turns medially to innervate the chin and ventral vibrissae. Uniting the proximal portion of the left CL nerve to the distal portion of the mylohyoid nerve $\left(\mathrm{CL}_{\mathrm{p}}\right.$ $\mathrm{MH}_{\mathrm{d}}$ ) directed the severed taste axons to regenerate into the mylohyoid muscle and ventral skin of the chin, rather than return to the tongue. Hamsters were euthanized 23 days after this unilateral operation.

Rats (Sprague-Dawley strain from Harlan Co.). The CL nerve was unilaterally transected in 32 rats, followed by the $\mathrm{CL}_{\mathrm{p}}-\mathrm{MH}_{\mathrm{d}}$ union, as with hamsters, and euthanasia after $8,21,28$, or 180 days. In 10 of these 32 rats, both IXth nerves were transected near the carotid bifurcation and the distal portion of the IXth nerve stump was avulsed. Eight days before euthanasia at 180 days the atrophic sheath and other remains of the CL nerve were transected near the tongue in another 4 of the 32 rats; this did not further reduce the prevalence of lingual axons.

Gerbils (Meriones unguiculatus from Tumblebrook Farms, $\boldsymbol{n}=9$ ). The left chorda tympani and lingual nerves were each transected proximal to their union near the auditory bulla. The distal stump of the lingual nerve and the distal and proximal stumps of the chorda tympani nerves were avulsed. All nine animals were euthanized 22 days after the operation. Eight days before euthanasia the atrophic sheath and other remains of the CL nerve were transected near the tongue.

\section{Histological Methods}

Hematoxylin and Silver Staining. Animals were deeply anesthetized with an i.p. injection of sodium pentobarbital. An infusion pump was used to perfuse the anesthetized animals intracardially with $250 \mathrm{ml}$ buffered $0.9 \% \mathrm{NaCl}(\mathrm{pH} 7.4$ ) containing $0.02 \%$ heparin and $0.5 \%$ procaine $\mathrm{HCl}$, followed by a $250 \mathrm{ml}$ solution of $4 \%$ formaldehyde, $1 \% \mathrm{NH}_{4} \mathrm{OH}$, and $15 \%$ sucrose. Serial, $10 \mu \mathrm{m}$ cross-sections of paraffin embedded tongues were stained with Heidenhain's iron hematoxylin to visualize taste buds. For the study of normal and regenerated axons, serial, $40 \mu \mathrm{m}$ sagittal frozen sections of fixed tongue were stained with Winkelmann's silver stain (Winkelmann, 1960), a reliable method for demonstrating cutaneous axons.

Fungiform taste bud volumes were assessed from cross-sectional profiles which typically involved three or four consecutive $10 \mu \mathrm{m}$ cross-sections for a normal taste bud. We used a graphics tablet to compute the area of camera lucida drawings of each hematoxylin stained taste bud profile, summed the profile areas for each taste bud, and multiplied by the $10 \mu \mathrm{m}$ section thickness to obtain the volume of every normal (right side) and experimental (left side) fungiform taste bud in seven experimental rats 180 days after interruption of the CL nerve.

Immunocytochemistry. Rat tongues were examined at 21 days $(\mathbf{n}=5)$ and 28 days $(\mathrm{n}=2)$ after interruption of the CL nerve. Anesthetized rats were perfused with $0.02 \%$ heparin and $0.5 \%$ procaine $\mathrm{HCl}$ in mammalian Ringer's solution followed by a mixture of $10 \%$ acetic acid and 70\% ethanol. The tongue was excised and placed in acid alcohol for $1 \mathrm{~h}$ and then cryoprotected and infiltrated (Barthel and Raymond, 1990). Cryostat sections, $10 \mu \mathrm{m}$ thick, were placed on gelatincoated slides, air dried, and stored at $-20^{\circ} \mathrm{C}$.

The slides with tissue sections were washed in $0.1 \mathrm{M}$ phosphate buffered saline (PBS), $\mathrm{pH} 7.4$, containing $0.4 \%$ Triton X-100 (TX) followed by $3 \%$ normal goat serum (Cappel, from Organon Teknika Corp.) in PBS/TX for 30-60 min and a $1 \mathrm{~h}$ incubation with the primary monoclonal antibody against keratin 19 (clone 4.62, Sigma; clone 170.4.12, Boehringer-Mannheim). The slides were rinsed in PBS after this and each subsequent step. Following incubation for $45-60 \mathrm{~min}$ with biotin-conjugated goat antibody against mouse IgG (Sigma), the tissue sections were exposed to Vectastain $A B C$ reagent (Vector Lab) for $30 \mathrm{~min}$ and reacted with 3,3'-diaminobenzidine (DAB: Sigma) as $0.5 \mathrm{mg} / \mathrm{ml}$ $\mathrm{DAB}, 0.04 \% \mathrm{NiCl}_{2}$, and $0.001 \% \mathrm{H}_{2} \mathrm{O}_{2}$.

Scanning Electron Microscopy. Twenty-eight days after CL nerve interruption three anesthetized rats were perfused with heparinized cacodylate buffer (0.1 M Na cacodylate, $\mathrm{pH} 7.35$ ) followed by $2 \%$ glutaraldehyde in cacodylate buffer. To avoid disorienting the filiform spines, the tongue was removed without rinsing the tongue surface. The tongue was dehydrated in an ethanol series, subjected to critical point drying, and sputtered with gold to a thickness of about $15 \mathrm{~nm}$. The surface of the tongue was examined with an ISI Model DS-130 scanning electron microscope.

\section{RESULTS}

About 90 fungiform papillae are scattered over the dorsal surface on each side of gerbil, hamster, and albino rat tongues. More than $95 \%$ of fungiform papillae contain a solitary oval fungiform taste bud (Fish et al., 1944; Cheal and Oakley, 1977; Miller and Smith, 1984). The fusiform or elongated taste cells define the axis of the taste bud. Many such cells extend a slender process into the taste pore, the narrow opening through the overlying squamous cell layer (Figs. 1A;5A,D).

\section{Classification of Fungiform Papillae After Interruption of the CL Nerve in Rats}

After interruption of the CL nerve, many fungiform taste buds degenerated completely, leaving an empty papilla. Based upon hematoxylin staining, residual taste buds were classified into two abnormal types.

Atrophic Fungiform Taste Buds. Atrophic taste buds had the oval shape characteristic of normal taste buds, but typically were abnormally small and lacking a visible taste pore (Fig. 1B,C). Atrophic buds contained several elongated cells that had keratin 19-like immunoreactivity (see below).

Remnants of Fungiform Taste Buds. Taste bud remnants consisted of a cluster of several rounded cells and generally a few elongated cells (Fig. 1D-H). Taste bud remnants were not observed in normal tongues, but were present as early as 8 days-the earliest post- 

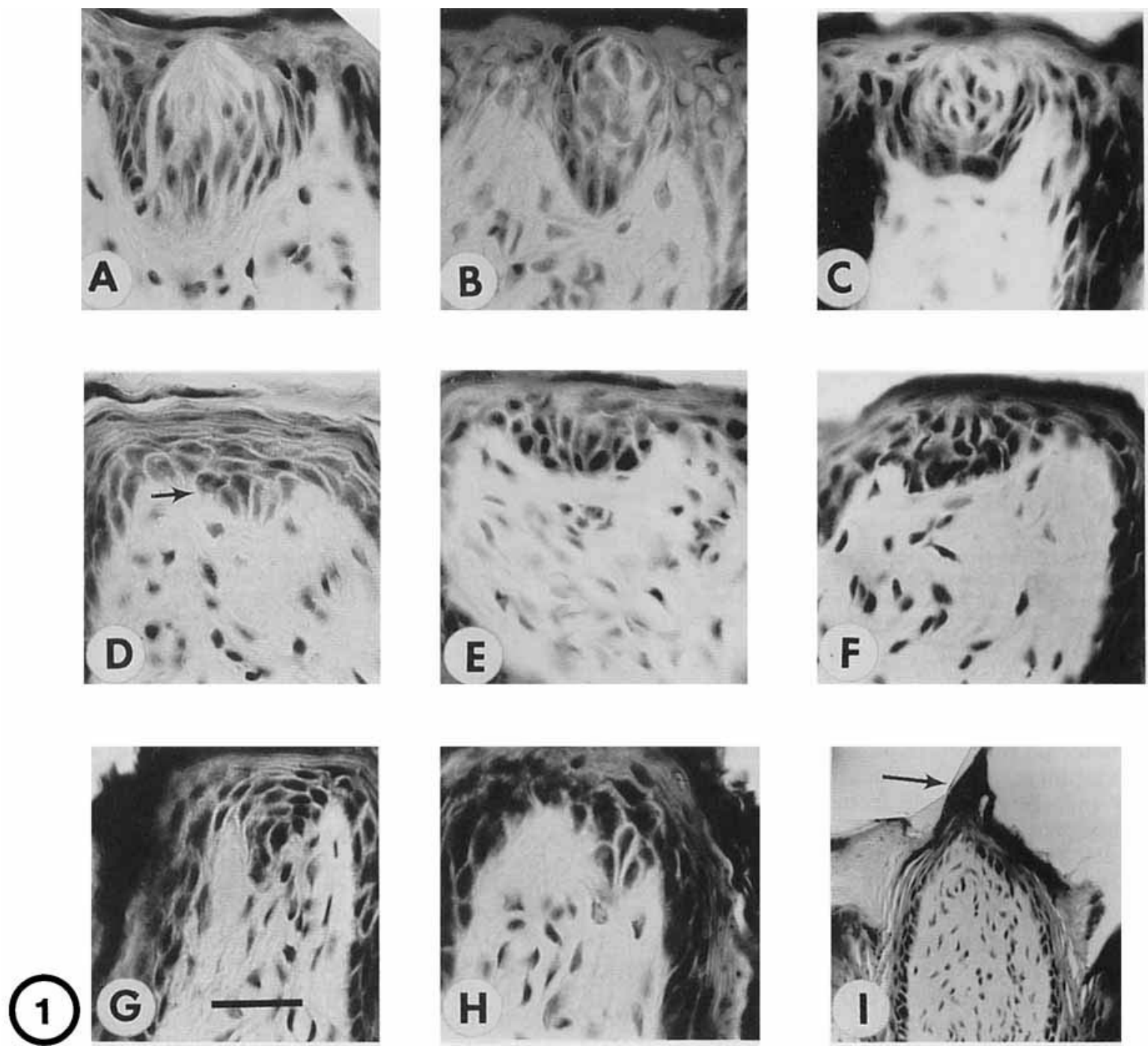

Fig. 1. Fungiform taste buds in rat. A: Normal. Interruption of the CL nerve caused degenerative changes in rat residual fungiform taste buds as represented in the following examples: atrophic fungiform taste buds at (B) 23 days and (C) 180 days after surgery; taste bud remnants at (D) 8 days (arrow), (E) 21 days, and (F-H) 180 days after

surgery. I: Fungiform papilla with no taste bud and a small filiformlike spine (arrow) at 8 days. Heidenhain's iron hematoxylin stain of $10 \mu \mathrm{m}$ cross-sections. Scale line in $\mathrm{G}$ is $25 \mu \mathrm{m}$ for $\mathrm{A}-\mathrm{H}$ and $98 \mu \mathrm{m}$ for I.

surgical time examined (Fig. 1D). Taste bud remnants observed 8-21 days after surgery (Fig. 1D,E) appeared similar to those seen after 180 days (Fig. 1F). They were never more than a fragment of a fungiform taste bud often a small collection of cells in the apical (Fig. 1D-F) or lateral (Fig. 1G,H) regions of the papilla.

Empty Fungiform Papillae. Empty fungiform papillae had no taste buds or clustered cells. Since $>95 \%$ of normal rat fungiform papillae have one taste bud (Fish et al., 1944), each empty papilla represented one lost taste bud. By as early as 8 days after CL interruption, an ectopic filiform spine extended from the apical surface of some empty fungiform papillae (Fig. 1I). An empty fungiform papilla could usually be identified from its large area and sometimes from the presence of an abnormal spine. Ectopic filiform spines were typically small and not pointed in the usual caudal direction (Fig. 2). They never occurred on fungiform papillae that contained an atrophic taste bud and only rarely occurred in conjunction with a taste bud remnant (Oakley et al., 1990).

Undetected Fungiform Papillae. There were 87 \pm 10 (mean \pm 1 sd) fungiform taste buds and papillae on the normal side of 21 rat tongues. Thus, a mean of 87 fungiform papillae was expected on the experimental side 180 days after CL nerve interruption. Experimental fungiform papillae contained either an atrophic taste bud, a taste bud remnant, or no taste bud. Since 


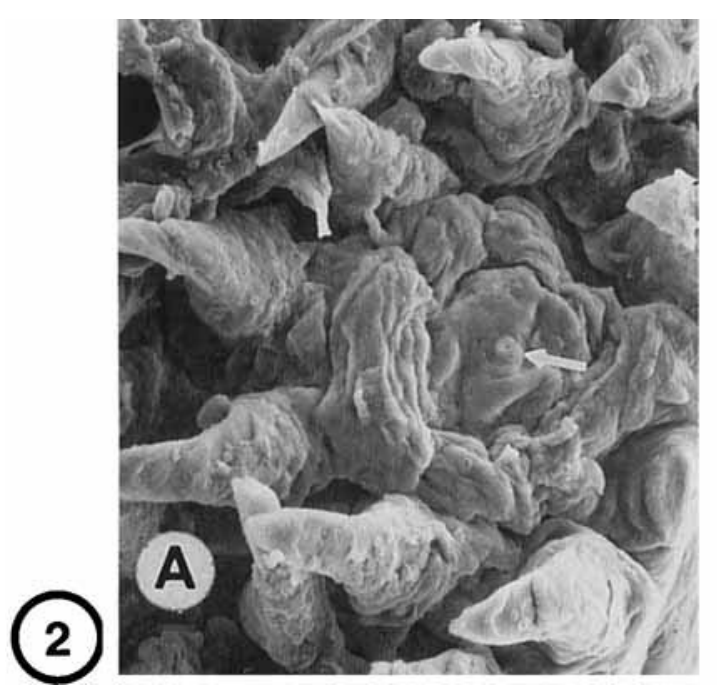

Fig. 2. SEM of filiform spines on rat tongue ipsilateral to $C L$ nerve interruption 28 days earlier. Most spines point caudally. A: Several robust filiform spines surround a fungiform papilla that may contain an atrophic taste bud and taste pore (arrow). B: Further rostrally one

a mean total of 70 was observed, there was a shortfall of 17 undetected fungiform papillae. Some small undetected fungiform papillae lacking a taste bud were probably indistinguishable from large undulations of the lamina propria or, if small and bearing a well-developed ectopic spine, were indistinguishable from ordinary filiform papillae (Oakley et al., 1990).

\section{Keratin 19-Like Immunoreactivity of Rat Fungiform Taste Buds After Interruption of the Chorda-Lingual Nerve}

In the epithelium of the anterior portion of the tongue, keratin 19-like IR is present only in elongated taste cells (Oakley, 1991). Two monoclonal antibodies to keratin 19 (MAbs 4.62 and 170.2.14) were used as cell markers to verify that the structures classified as atrophic taste buds and remnants of taste buds were actually attenuated fungiform taste buds. Keratin 19like immunoreactivity was pronounced in the elongated cells of normal fungiform taste buds and was not detectable in neighboring rounded cells or in the squamous cells that contain more common lingual keratins (Fig. 3A). Residual taste buds present 21 days after CL interruption had keratin 19-like IR. Specifically, atrophic taste buds contained several elongated immunoreactive cells which had the swollen keratinrich basal processes characteristic of normal taste cells (Fig. 3B). Remnants never had more than a few immunoreactive taste cells (Fig. 3C). Hence, interruption of the CL nerve led to a demonstrable loss of elongated taste cells in remnants of taste buds and in some atrophic taste buds. Both normal and atrophic taste buds appeared less oval than hematoxylin stained taste buds because some surrounding cells were keratin 19 negative.

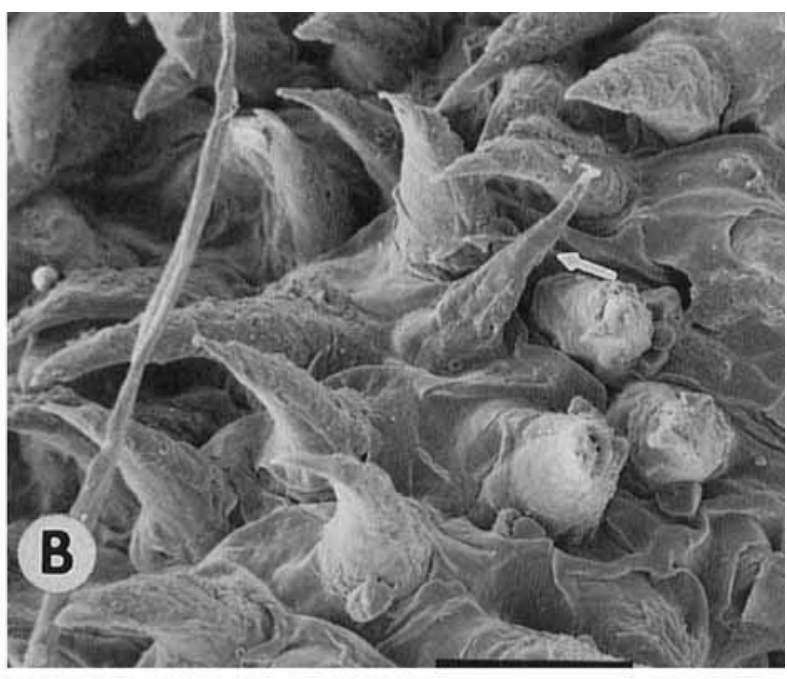

filiform spine (arrow) is provisionally identified as ectopic because it is slender, curved anterolaterally rather than caudally, and not in the rostrocaudally directed rows of spines. Scale line is $10 \mu \mathrm{m}$ for A and B.

\section{Prevalence of Fungiform Taste Buds as a Function of Time After Interruption of the Chorda-Lingual Nerve in Rats}

Table 1 gives the number of fungiform papillae in each of the four classes as a function of days after CL nerve interruption. As early as 8 days after surgery, $28 \%$ of rat fungiform papillae were empty or undetected. Between 8 and 23 days a statistically significant decrease in the number of taste bud remnants (from 40 to $21 ; P<0.05$, t-test) was paralleled by a quantitatively corresponding increase in the number of atrophic taste buds (from 25 to $39 ; P<0.05$ ). Between 23 and 180 days the number of remnants declined further (from 21 to 11: $P<0.02$ ), while the undetected papillae increased significantly from 6 to $17(P<0.02)$ and atrophic buds remained constant. This is consistent with the slow degeneration of additional taste bud remnants. It would be more difficult to detect fungiform papillae that, after losing their taste bud remnant, continued to shrink and extend an ectopic spine (Oakley et al., 1990).

Since we counted $70 \pm 10$ fungiform papillae on the experimental side of seven tongues vs. $87 \pm 10$ papillae on the normal side of 21 tongues, a mean of 17 fungiform papillae was undetected at 180 days. Consequently, about $50 \%$ (49) of rat fungiform taste buds had either disappeared completely $(21$ empty +17 undetected $=38$ buds) or persisted only as small clusters of remnant cells (11 buds).

\section{Morphometry of Denervated Fungiform Taste Buds}

To demonstrate quantitatively that atrophic taste buds and taste bud remnants were smaller than normal, we measured the volume of the 241 atrophic 


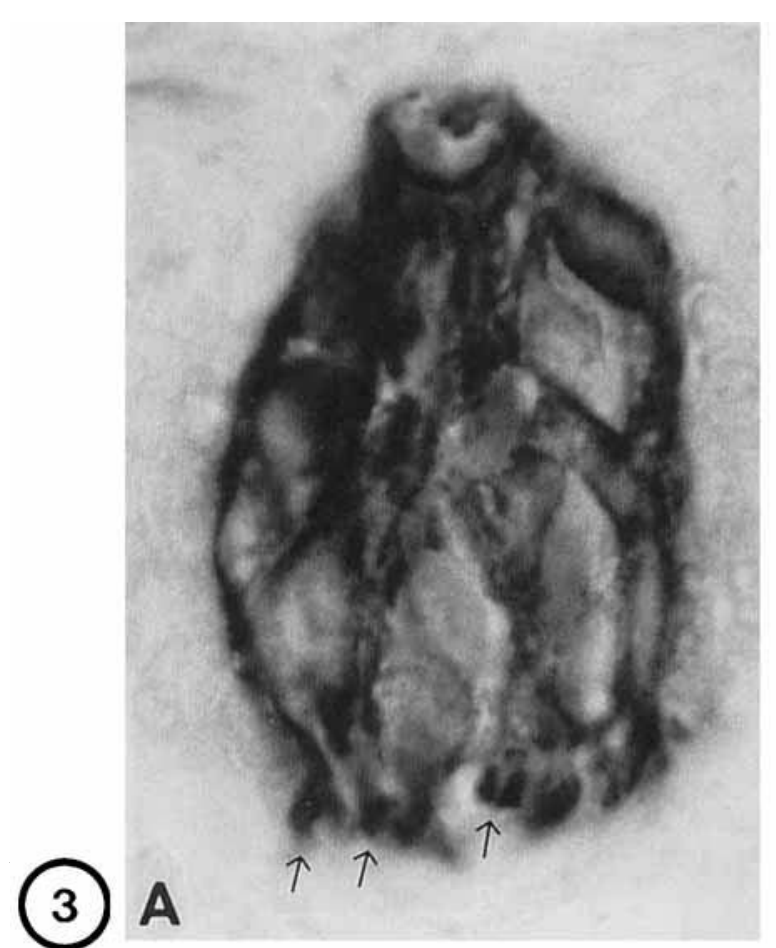

Fig. 3. A: A monoclonal antibody specific to keratin 19 (MAb $170.2 .14 ; 1: 200$ ) reacted only with cells in rat fungiform taste buds. Light ovals are cell nuclei. B: This atrophic taste bud has several elongated keratin 19-like immunoreactive cells (MAb 4.62;1:100). The basal portion of the cells was less prominent in this section. C:
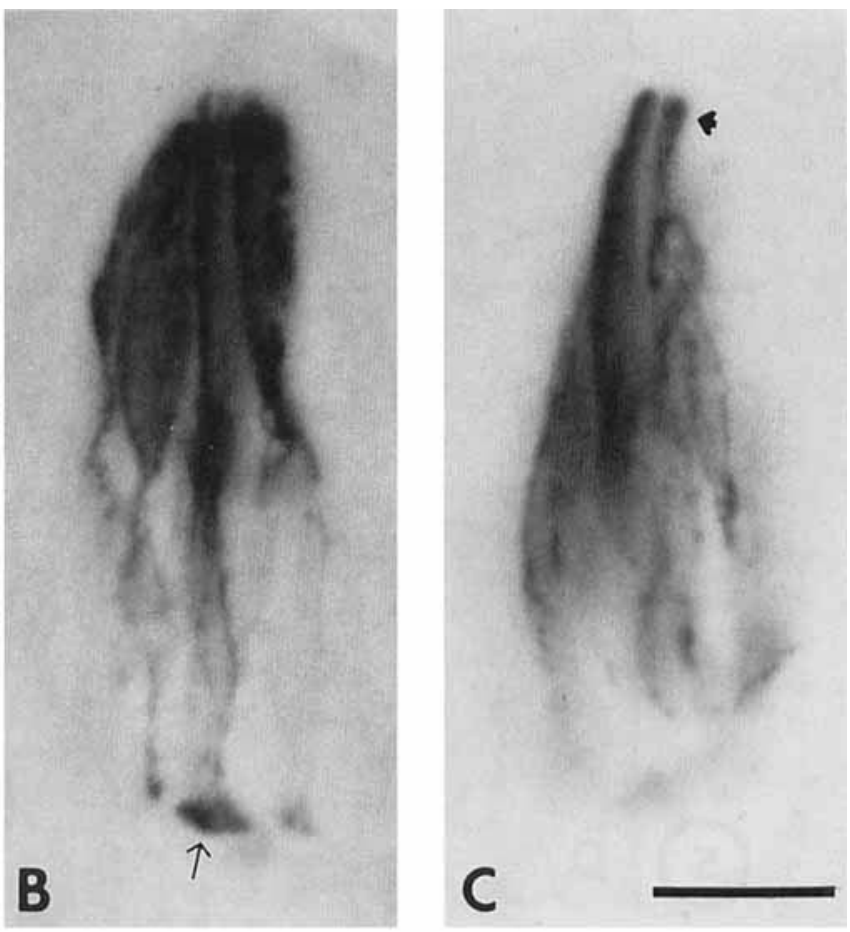

This taste bud remnant was restricted to one histological section. It contained two elongated cells with intense keratin 19-like IR in their tapered apical process (arrowhead) (MAb 4.62; 1:100). Arrows in A and $B$ show the intensely immunoreactive enlarged basal process of taste bud cells. Scale line in C is $10 \mu \mathrm{m}$ for A-C.
TABLE 1. Loss or deterioration of rat fungiform taste buds associated with unilateral interruption of the chorda-lingual nerve ${ }^{1}$

\begin{tabular}{cccccc}
\hline Days & N & $\begin{array}{c}\text { Atrophic } \\
\text { TB }\end{array}$ & $\begin{array}{c}\text { TB } \\
\text { remnant }\end{array}$ & $\begin{array}{c}\text { Empty } \\
\text { PAP }\end{array}$ & $\begin{array}{c}\text { Undetected } \\
\text { PAP }\end{array}$ \\
\hline 8 & 5 & $25 \pm 10$ & $40 \pm 14$ & $17 \pm 8$ & $9 \pm 7$ \\
23 & 9 & $39 \pm 9^{*}$ & $21 \pm 7^{*}$ & $19 \pm 8$ & $6 \pm 6$ \\
180 & 7 & $38 \pm 10$ & $11 \pm 7^{* *}$ & $21 \pm 7$ & $17 \pm 10^{*}$ \\
\hline
\end{tabular}

${ }^{1}$ Days $=$ days after unilateral interruption of the chorda-lingual nerve. $\mathrm{N}=$ number of animals. The number of undetected fungiform papillae on the experimental side of the tongue is given for each group by the difference between mean on the normal side $(91,85$, or 87 taste buds) and the sum of the atrophic, remnant, and empty classes. The entries are the mean number of fungiform taste buds or papillae \pm 1 sd: Asterisks indicate an entry that differs significantly from the entry immediately above (t-test).

$* P<0.05$.

$* * P<0.02$.

fungiform taste buds and 69 taste bud remnants in seven animals and compared these to the volumes of 480 normal taste buds in six of these animals. The average volume of normal taste buds was nearly twice that of atrophic taste buds and almost four times that of taste bud remnants. Consequently, there was virtually no overlap between the volume distributions of normal taste buds and remnants (Fig. 4).

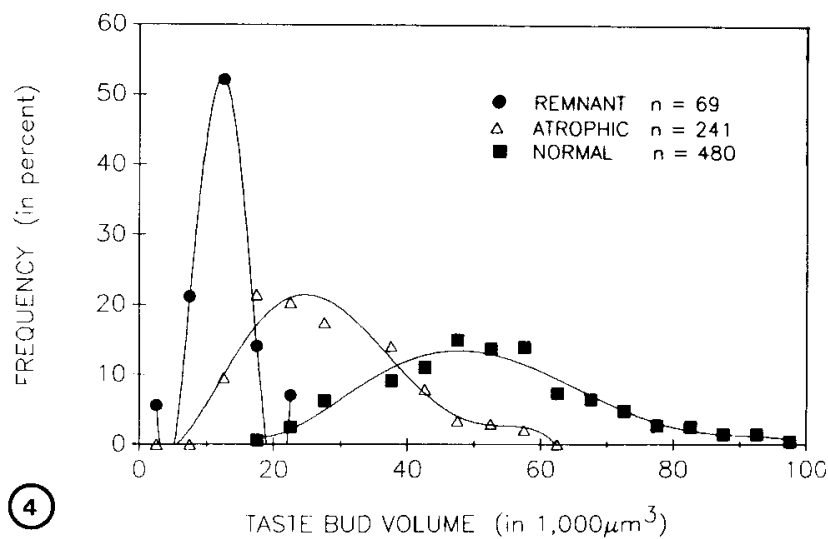

Fig. 4. Frequency distributions of the volume of 69 remnants, 241 atrophic taste buds, and 480 normal taste buds measured from camera lucida drawings after interruption of the CL nerve in rats (see Materials and Methods). The taste bud category, polynomial order, and Pearson correlation coefficients for the best-fit polynomial curves are as follows: remnants, fourth order, $r=+1.0$; atrophic, fifth order, $r=$ +.988 ; and normal, fifth order, $r=+.982$. The modes of the best-fit curves are $12,000,22,000$, and $44,000 \mathrm{\mu m}^{3}$ for the remnant, atrophic and normal taste bud distributions, respectively. The values are unadjusted for histological shrinkage. 

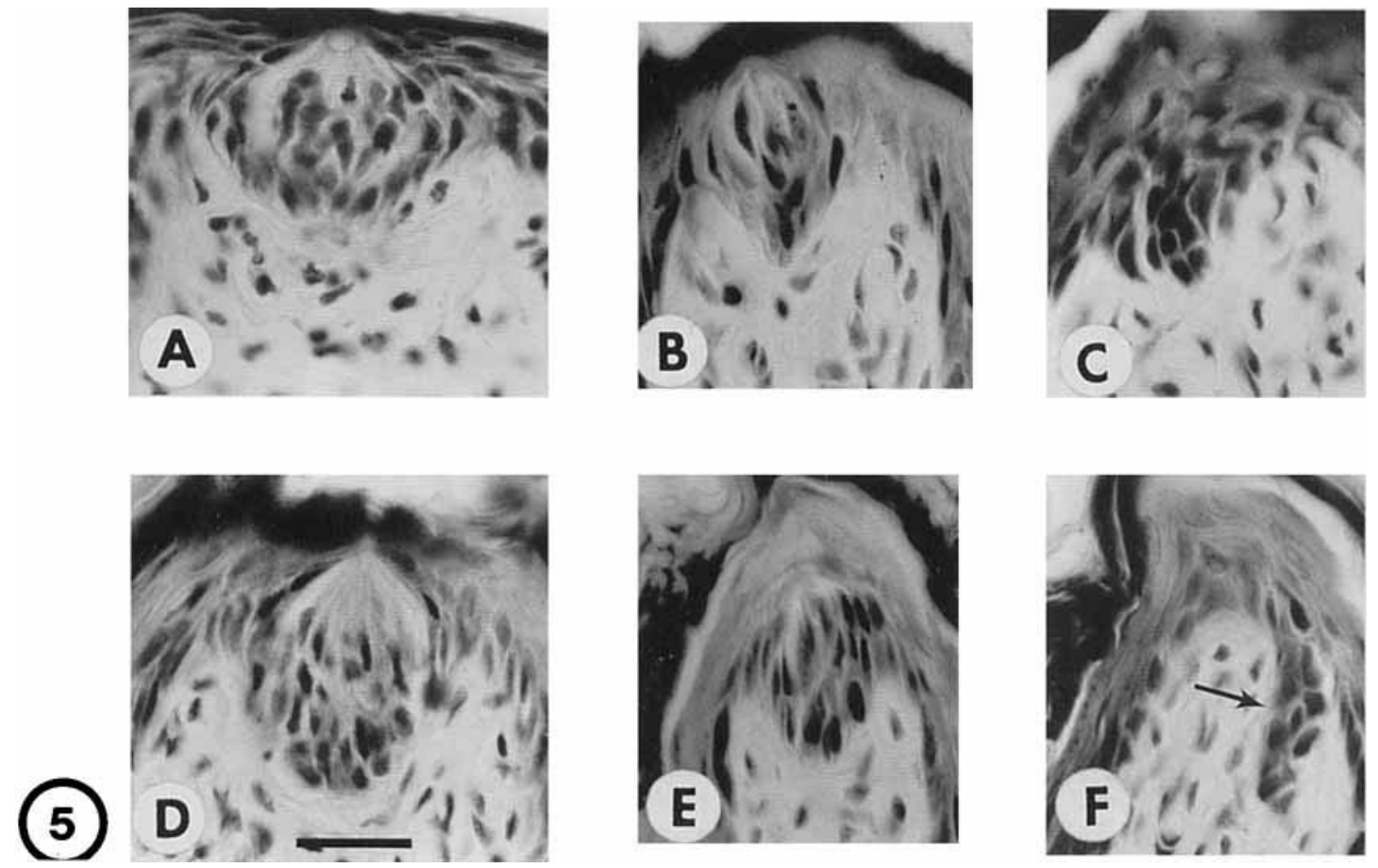

Fig. 5. Twenty-three days after unilateral interruption of the CL nerve, normal fungiform taste buds were present on the contralateral side of the (A) hamster tongue, while (B) atrophic taste buds and (C) taste bud remnants were present ipsilaterally. Similarly gerbils had
(D) contralateral normal taste buds, ipsilateral (E) atrophic taste buds, and (F) taste bud remnants (arrow) 22 days after surgery. Heidenhain's iron hematoxylin stain of $10 \mu \mathrm{m}$ cross-sections. Scale line in $\mathrm{D}$ is $25 \mu \mathrm{m}$ for $\mathrm{A}-\mathrm{F}$.

\section{Comparative Studies of Fungiform Taste Bud Degeneration in Rodents}

The observations of Whitehead et al. (1987) that most hamster fungiform taste buds survived CL nerve interruption prompted us to compare the survival of fungiform taste buds in rat, hamster, and gerbil 21-23 days after interrupting the CL nerve. The normal fungiform taste buds on the unoperated side of the hamster and gerbil tongue resembled those of rats (Fig. 5A,D). Similarly, the fungiform taste buds that survived on the experimental side of hamster and gerbil tongues were divisible into the atrophic (Fig. 5B,E) and remnant (Fig. 5C,F) classes identified in rats. In gerbils 67 of 94 fungiform papillae were either empty or undetected vs. 24 of 92 in hamsters (Table 2). The extent of taste bud loss and deterioration suggest that the nerve-dependence of fungiform taste buds was greatest in gerbils and least in hamsters.

\section{Silver Staining of Epithelial Axons in Rats}

The Winkelmann silver procedure proved to be reliable and sensitive; axons could be traced to the base of residual taste buds. A fungiform papilla was considered to be innervated when there were silver-stained axons within the three central $40 \mu \mathrm{m}$ thick sections that encompass a normal fungiform papilla. We examined parasagittal frozen sections of 11 rat tongues for epithelial axons $8,21,28$, and 180 days after interruption of the CL nerve. A few axons were evident in $67 \%$ of rat fungiform papillae 8 days after interruption of the CL nerve. Thus, although axons were markedly reduced, they were never totally eliminated from rat fungiform papillae; by 4 weeks after CL interruption axons were present in every fungiform papilla.

\section{Silver Staining of Axons in Gerbil Fungiform Papillae}

We focussed on the gerbil's tongue in assessing the nerve dependency of fungiform taste buds, since transecting the lingual nerve and crushing the chorda tympani nerve virtually eliminated axons in the gerbil's fungiform papillae for at least 8 days (Cheal and Oakley, 1977). As in rats, normal fungiform papillae of gerbils are heavily innervated (Fig. 6A). More than two-thirds of gerbil fungiform taste buds were completely degenerated 22 days after unilateral transection of both the chorda tympani and lingual nerves. These fungiform taste buds must have been nervedependent.

One could consider the residual taste buds to be nerve-independent, if their papilla were no more frequently innervated than empty papillae. In four gerbils 32 of 144 empty papillae lacked axons (Fig. 6E). Thus, by chance alone, 20 of the 88 fungiform papillae with residual taste buds should have lacked axons. Yet none of the 88 lacked axons $(P<0.01$, binomial test).

Axons were sometimes less abundant in papillae with taste buds (Fig. 6B) than without taste buds (Fig. 
TABLE 2. Number of fungiform taste buds and empty and undetected fungiform papillae in gerbils, rats, and hamsters 21-23 days after unilateral transection of the chorda-lingual nerve

\begin{tabular}{|c|c|c|c|c|c|c|c|}
\hline \multirow[b]{2}{*}{ Days } & \multirow[b]{2}{*}{$\mathbf{N}$} & \multirow[b]{2}{*}{ Species } & \multirow{2}{*}{$\begin{array}{c}\text { Left } \\
\text { (normal) }\end{array}$} & \multicolumn{4}{|c|}{ Right $=$ experimental side of tongue } \\
\hline & & & & Atrophic* & Remnant & Empty & Undetected \\
\hline 22 & 5 & gerbil & $94 \pm 15$ & $20 \pm 11$ & $7 \pm 4$ & $41 \pm 4$ & $26 \pm 14$ \\
\hline 21 & 6 & rat & $86 \pm 9$ & $42 \pm 9$ & $22 \pm 5$ & $18 \pm 5$ & $6 \pm 6$ \\
\hline 23 & 5 & hamster & $92 \pm 10$ & $59 \pm 9$ & $9 \pm 4$ & $7 \pm 1$ & $17 \pm 8$ \\
\hline
\end{tabular}

${ }^{*} P<0.025$, number of atrophic taste buds: gerbil $<$ rat $<$ hamster, t-tests.
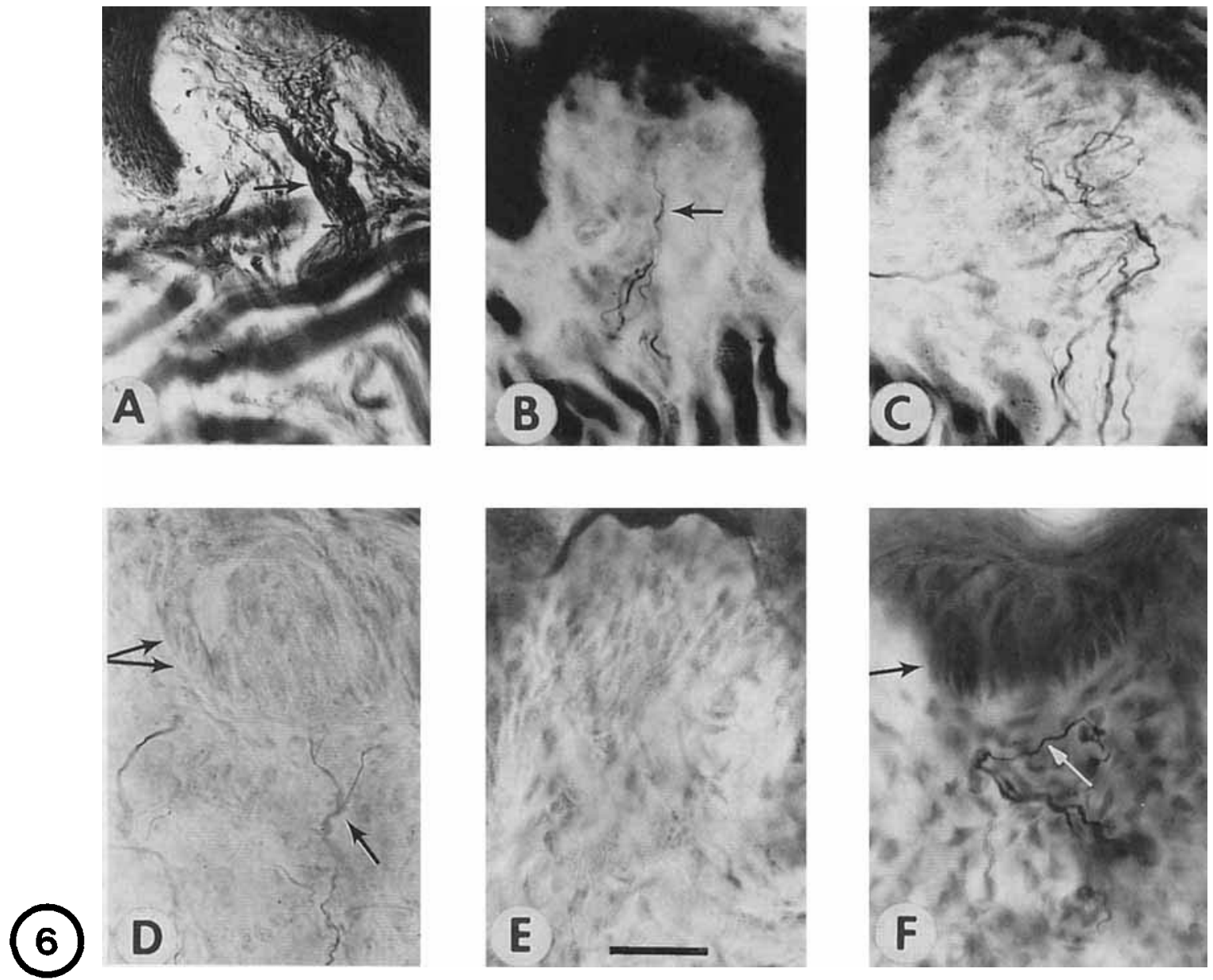

Fig. 6. A: A profusely innervated normal gerbil fungiform taste bud. The arrow points to a stout fascicle of axons before dispersion in the papilla. In gerbils 22 days after surgery there were papillae with (B) a few axons and a residual fungiform taste bud or (C) additional axons and no taste bud. D: Some sizeable fungiform taste buds (double arrow) remained innervated (single arrow) 8 days after interruption

$6 \mathrm{C})$. This may reflect variation in the proportion that were taste axons.

\section{Spatial Distribution of Fungiform Papillae in Silver-Stained Gerbil Tongue}

Axons in fungiform papillae were only rarely found in the gerbil's tongue 7-8 days after interruption of the chorda tympani and lingual nerves (Cheal and Oakley, of the CL nerve (rat). E: A gerbil fungiform papilla with no axons or taste bud 22 days after surgery. F: Light arrow shows axons and dark arrow an innervated taste bud counterstained by methyl green 28 days after surgery in rat. Scale line in $\mathrm{E}$ is $98 \mu \mathrm{m}$ for $\mathrm{A}, \mathrm{B}$ and $25 \mu \mathrm{m}$ for $\mathrm{C}-\mathrm{F}$.

1977). However, 22 days after transection of the chorda tympani and lingual nerves several fungiform papillae were reinnervated in four gerbils (e.g., filled circles and triangles, Fig. 7). Residual taste buds tended to be found rostrally; all were innervated (filled triangles, Fig. 7). Papillae with axons but no taste buds or papillae lacking both axons and taste buds were widely scattered (filled and open circles, respectively, in Fig. 7). 


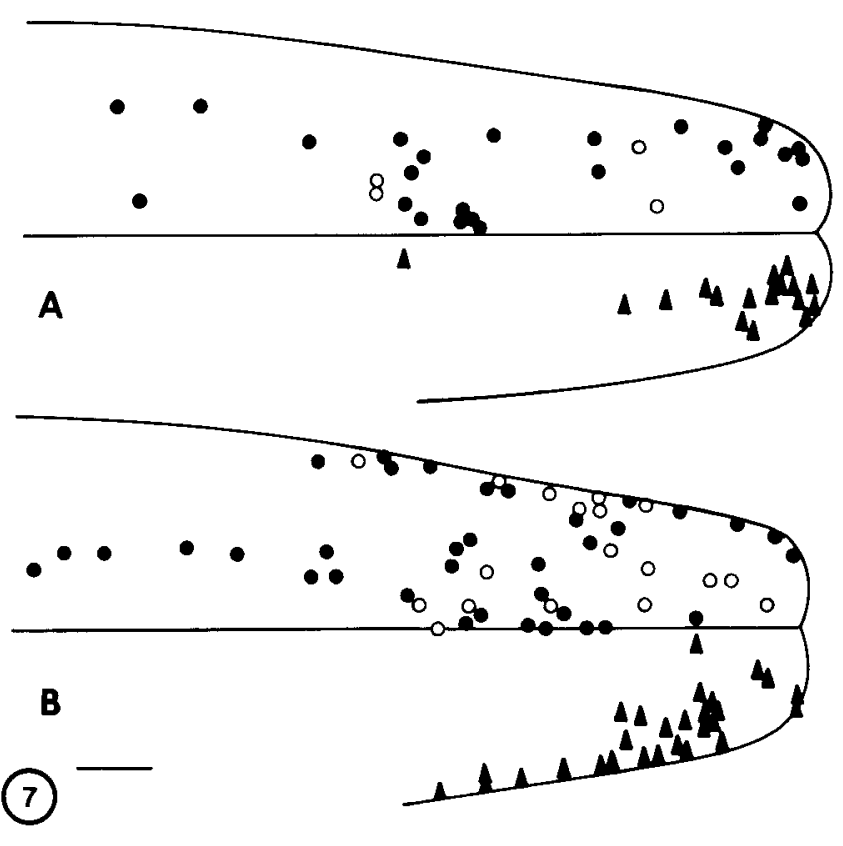

Fig. 7. The distribution of taste buds or axons in fungiform papillae is shown for two gerbils $(A, B) 22$ days after interruption of the $C L$ nerve. The positions of fungiform papillae were determined by reconstruction from serial, $40 \mu \mathrm{m}$, parasagittal, silver-stained frozen sections. Filled triangles = fungiform papillae with taste buds and axons (for clarity displayed separately on the right side of the tongue); filled circles $=$ fungiform papillae with axons but no taste bud; open circles $=$ papillae with no axons or taste bud. Scale line $=1 \mathrm{~mm}$.

The gerbil's tongue represented in Figure 7B is an example of the high correlation between taste buds and axons. Of the 54 experimental fungiform papillae detected, 18 lacked axons. Consequently, if the 28 residual fungiform taste buds of this gerbil were sustained independently of innervation (hypothesis of neurotrophic independence), by chance about 9-10 should have lacked axons, but all 28 were innervated.

\section{Interruption of the IX and CL Nerves Eliminated Vallate and Foliate Taste Buds}

Because the single vallate papillae is bilaterally innervated, we transected both IXth nerves in 10 rats. Since several foliate taste buds will survive IXth nerve transection, we also unilaterally transected the CL nerve and performed a $\mathrm{CL}_{\mathrm{p}}-\mathrm{MH}_{\mathrm{d}}$ nerve cross to discourage CL regeneration into the foliate papillae. We examined five rats at 8 days and five others at 23 days after surgery. All taste buds had completely disappeared from the vallate papilla by 8 days and from the foliate papilla by 23 days after surgery.

\section{DISCUSSION}

Nerve transection confirmed the prevailing view that all vallate and foliate taste buds in rat, including those innervated by the chorda lingual nerve, exhibit total nerve-dependence (Oakley, 1970). In respect to the nerve-dependence of fungiform taste buds, interruption of the CL nerve resulted in the outright loss of
$71 \%$ of fungiform taste buds in gerbils, $28 \%$ in rats, and $26 \%$ in hamsters after 3 weeks. These calculations properly include undetected fungiform papillae that were expected, yet not detected. Simultaneous counts on the normal control side identified a mean of 87 fungiform papillae, which consequently was the number expected on experimental side.

Most residual taste buds were small. While some normal taste buds were also small, 35\% of atrophic taste buds were smaller than all normal taste buds. Hence, the preferential survival of small normal taste buds cannot by itself account for these atrophic taste buds. The second class of residual taste buds, taste bud remnants, were even smaller and more abnormal. Not only were they smaller than virtually all normal and most atrophic taste buds, but they were also non-oval subportions of taste buds that had few elongated cells. Taste bud remnants were not observed in healthy tongues. Three observations argue that taste bud remnants were fragments derived from fungiform taste buds: 1) their elongated cells reacted with antibodies to keratin 19 that are specific markers for taste cells in normal and atrophic fungiform taste buds; 2) during a period of documented increased innervation, a decrease occurred in the number of taste bud remnants that paralleled a quantitatively reciprocal increase in atrophic taste buds; and 3) with few exceptions taste bud remnants shared with atrophic buds the capacity to prevent the outgrowth of an ectopic filiform spine (Oakley et al., 1990).

The conclusions of this investigation do not depend upon the subdivision of residual taste buds into atrophic and remnant classes. That aside, it was useful to distinguish two levels of deterioration. It was more efficient to monitor temporal shifts in taste bud size by counting the relative abundance of two classes than by measuring all taste bud volumes. For example, shifts in atrophic and remnant taste bud counts imply that early on some taste bud remnants enlarged into atrophic buds, whereas later on many taste bud remnants failed to survive and disappeared. By their abundance taste bud remnants also demonstrated that taste buds can survive as distorted subportions with few elongated cells. When no elongated cells were evident in hematoxylin staining, remnants were for two reasons classified as residual taste buds rather than lost buds. First, although infeasible to apply to all papillae, had it been used, the sensitive assay for keratin 19-like IR might have revealed elongated cells. Second, classifying all remnants as residual taste buds insured a more conservative assessment of taste bud losses (Hard af Segerstad et al., 1989).

Ganchrow and Ganchrow (1989) found that extirpation of the facial nerve in 4-5-week-old rats eliminated $90 \%$ of the ipsilateral fungiform taste buds at the tip of the tongue examined 30-90 days later. These apparently stable, conservatively appraised, taste bud losses suggest that fungiform taste buds in young rats are especially vulnerable to denervation or that facial nerve interruption was particularly effective.

In the present investigation the total quantity of taste bud tissue lost after CL interruption can be calculated from the numbers of atrophic taste buds, of 
remnants of taste buds, and of missing taste buds multiplied by the corresponding volume losses of $50 \%$ for atrophic taste buds, $75 \%$ for taste bud remnants, and $100 \%$ for missing taste buds. Total gustatory tissue losses were $90 \%$ for gerbils, $75 \%$ for rats, and $65 \%$ for hamsters. The reduced number of keratin 19 positive cells in residual taste buds indicates a loss of taste cells.

Notwithstanding these major losses of gustatory tissue, it is possible that the residual taste buds arose from a limited subset of nerve-independent stem cells that gave rise to differentiated taste cells. In this view residual fungiform taste buds would constitute an exception to the rule that mammalian taste buds are neurotrophically maintained. Consequently, a second objective was to address the possibility that innervation supported the residual taste buds. Three observations support the nerve-dependence of residual taste buds. First, during the period when an increasing percentage of experimental fungiform papillae in rats became innervated-from $67 \%$ at 8 days ( $n=3$ rats) to $99 \%$ at $3-4$ weeks $(n=5)$-several taste bud remnants appeared to enlarge into atrophic taste buds. Second, we evaluated in gerbils whether the co-occurrence of residual taste buds and axons was likely to be coincidental. The innervation status of all fungiform papillae was comprehensively assessed with the Winkelmann silver staining procedure. If the joint occurrence of residual taste buds and axons were merely coincidental, one would expect, given $22 \%$ of empty fungiform papillae with no axons, that a similar percentage of residual taste buds would lack axons. But all fungiform papillae with residual taste buds were innervated. Third, every fungiform papilla that lacked axons also lacked a taste bud. These data support the view that gerbil fungiform taste buds are nerve-dependent.

Contralateral axons are reported to sprout no more than $2 \mathrm{~mm}$ across the midline of the rat tongue (Kinnman and Aldskogius, 1988). In the present investigation axons were present in rat fungiform papillae situated more than $2-4 \mathrm{~mm}$ lateral to the midline 8 days after transection of the rat CL nerve. An 8 day postoperative period is sufficient for the degeneration of interrupted CL axons (Cheal and Oakley, 1977; Whitehead et al., 1985) but too brief for CL regeneration. Crushed CL axons take more than 9-10 days to return to the fungiform papillae in gerbils (Cheal and Oakley, 1977), and such axons would have to regenerate twice as far in the larger tongue of the rat. Hence, preliminary consideration of the origins of residual axons in rats suggests that the ipsilateral $\mathrm{CL}$ nerve is not the sole source of fungiform axons.

After disruption of the chorda tympani nerve, electron microscopy revealed axon profiles in residual taste buds in rats (Hard af Segerstad et al., 1989) but not in hamsters (Whitehead et al., 1987). However, the paucity of axons within residual taste buds would be a moot issue if taste buds were neurotrophically supported by contact between axons and cells beneath taste buds. After complete surgical extirpation of the fungiform papilla, neither the taste bud nor the papilla regenerated, whereas after extirpation of the upper half of the fungiform papilla, securely including the taste bud, both bud and papilla regenerated within 2 weeks (Hellekant et al., 1987). Apparently, some stem cells beneath the extirpated taste bud survived and gave rise to a new taste bud.

In summary, appropriate nerve interruptions led to the complete disappearance of vallate and foliate taste buds in rats and led to quantified losses and deterioration of fungiform taste buds in gerbils, rats, and hamsters. In gerbils, where innervation status after chordalingual nerve interruption has been most directly assessed, the invariant association of residual fungiform taste buds with axons argues for the nerve-dependence of surviving taste cells.

\section{ACKNOWLEDGMENTS}

We thank C. DeSibour and L. Wong for technical assistance. This work was supported in part by NIH grant DC-00083.

\section{REFERENCES}

Barthel, L.K., and Raymond, P.A. (1990) Improved method for obtaining 3-microns cryosections for immunocytochemistry. J. Histochem. Cytochem., 38:1383-1388.

Cheal, M.L., and Oakley, B. (1977) Regeneration of fungiform taste buds: Temporal and spatial characteristics. J. Comp. Neurol., 172. $602-626$.

Cheal, M.L., Dickey, W.P., Jones, L.B., and Oakley, B. (1977) Taste fiber responses during reinnervation of fungiform papillae. J. Comp. Neurol., 172:627-646.

Farbman, A.I. (1969) Fine structure of degenerating taste buds after denervation. J. Embryol. Exp. Morphol., 22:55-68.

Fish, H.S., Malone, P.D., and Richter, C.P. (1944) The anatomy of the tongue of the domestic Norway rat. I. Anat. Rec., 89:429-440.

Ganchrow, J.R., and Ganchrow, D. (1989) Long-term effects of gustatory neurectomy on fungiform papillae in the young rat. Anat. Rec., $225: 224-231$

Guth, L. (1971) Degeneration and regeneration of taste buds. In: Handbook of Sensory Physiology, Vol. 4, Chemical Senses, Part 2. L.M. Beidler, ed. Springer, New York, pp. 63-74.

Hard af Segerstad, C., Hellekant, G., and Farbman, A.I. (1989) Changes in number and morphology of fungiform taste buds in rat after transection of the chorda tympani or chorda-lingual nerve. Chem. Senses, 14:335-348.

Hellekant, G., Kasahara, Y., Farbman, A.I., Harada, S., and Hard af Segerstad, C. (1987) Regeneration ability of fungiform papillae and taste-buds in rats. Chem. Senses, 12:459-465.

Kinnman, E., and Aldskogius, H. (1988) Collateral reinnervation of taste buds after chronic sensory denervation: A morphological study. J Comp. Neurol, 270:569-574.

Miller, I.J., Jr, and Smith, D.V. (1984) Quantitative taste bud distribution in the hamster. Physiol. Behav., 32:275-285.

Oakley, B. (1970) Reformation of taste buds by crossed sensory nerves in the rat's tongue. Acta Physiol. Scand., 79:88-94.

Oakley, B. (1985) Trophic competence in mammalian gustation. In: Olfactory and Gustatory Influences on the Central Nervous System. D. Pfaff, ed. The Rockefeller University Press, New York, pp 92-103.

Oakley, B. (1991) Neural-epithelial interactions in taste bud regeneration. In: Regeneration of Vertebrate Sensory Receptor Cells. J. Whelan, ed. Ciba Foundation Symposium, Wiley, London, pp. 277 287.

Oakley, B., Wu, L.-H., Lawton, A., and DeSibour, C. (1990) Neural control ectopic filiform spines in adult tongue. Neuroscience, 36 : $831-838$

Whitehead, M.C., Beeman, C.S., and Kinsella, B. (1985) Distribution of taste and general sensory nerve endings in fungiform papillae of the hamster. Am. J. Anat., 173:185-201.

Whitehead, M.C., Frank, M.E., Hettinger, T.P., Hou, L.-T., and Nah, H.-D. (1987) Persistence of taste buds in denervated fungiform papillae. Brain Res., 405:192-195.

Winkelmann, R.K. (1960) Nerve Endings in Normal and Pathologic Skin. C.C. Thomas, Springfield. 